\title{
Trudi C. Miller
}

\section{El funcionamiento del sector público}

Un punto de inflexión conceptual (*)

SUMARIO: PERSPECTTVA GENERAL: EL PUNTO DE INFLEXION. CAPITULO 1: LA PERSPECTIVA DE LA CIENCIA NATURAL. CAPITULO 2: CAMBIO INTERADMINISTRATIVO. CAPITULO 3: ¿POR QUE CRECE LA ADMINISTRACION? CAPITULO 4: SISTEMAS DE INFORMACION. CAPITULO 5: UNA PERSPECTIVA DEMOGRAFICA. CAPITULO 6: UNA PERSPECTIVA POLITICA. CAPITULO 7: UNA PERSPECTIVA FINANCIERA PUBLICA. CAPITULO 8: MODELOS DE DIRECCION Y RESPONSABILIDAD. CAPITULO 9: UNA PERSPECTIVA DE CIENCIA MARCO.

\section{PERSPECTIVA GENERAL: EL PUNTO DE INFLEXION}

Parece que nos hallamos en un punto de inflexión en lo que atañe a la teoría y la práctica sobre el funcionamiento del sector público. Como resultado de la actividad política, se ha reducido la tasa de crecimiento del gasto nacional en el sector público, y se ha planteado un debate sobre las teorías y métodos científicos en ámbitos atinentes al funcionamiento del sector público. Puede que esté surgiendo un nuevo marco de comprensión de la Administración moderna.

(*) El presente trabajo fue publicado originalmente en el libro Public Sector Perfomance: a conceptual turnig point, Johns Hopkins University Press. El INAP y la Redacción de DoCUMENTACION ADMINISTRATIVA desean dejar constancia de su agradecimiento al autor y editores del trabajo, por la autorización concedida para la traducción al castellano y reproducción aquí.

Aunque el trabajo es una introducción a una obra colectiva, que remite por ello en numerosas ocasiones a otras partes de la misma, se ha seleccionado por el interés que presenta como panorámica general del estado del análisis y del debate científico sobre el funcionamiento del sector público. 
Este libro enjuicia la doctrina sobre varias disciplinas relevantes: ciencia política, Administración pública, políticas públicas, Hacienda pública y ciencia de la dirección. La mayoría de las valoraciones son críticas, desafiando muchas de las innovaciones que los científicos sociales hacen a la objetividad, el rigor, la exactitud y el conocimiento. Al tiempo, sus capítulos revelan un intenso interés y entusiasmo intelectual por algunas ideas nuevas y otras viejas. En conjunto, sugieren que la ciencia social puede estar «despegando» hacia nuevos niveles de madurez metodológica y teórica.

Los autores presentan diversas perspectivas sobre la investigación y la práctica. Como editor, he situado sus valoraciones entre un capítulo introductorio, que se centra en la crítica de investigaciones y aproximaciones directivas del pasado, y un capítulo final, que destaca lo que parece ser un paradigma emergente de «diseño científico» para la ciencia política, las políticas públicas y la Administración. Mi estudio general y mi conclusión están estrechamente relacionados, porque describo el punto de inflexión como un cambio en las presunciones empíricas subyacentes sobre dinámica y estructura social. Arguyo que la crítica de los autores refleja errores en las presunciones básicas que rodean la «ciencia natural» convencional en su aproximación a los sistemas sociales. Las presunciones empíricas subyacentes a mi visión de la alternativa de "diseño científico» proceden de los resultados de las investigaciones de los autores. Confío en que estas presunciones sean más exactas para los sistemas políticos. Algunos lectores pueden preferir otros marcos de comprensión de la crítica y optimismo de estos capítulos. En última instancia, el debate sobre la existencia o naturaleza del «punto de inflexión» se decidirá por los futuros historiadores.

\section{LA PERSPECTIVA DE LA CIENCIA NATURAL}

Los autores de esta obra son críticos con la investigación convencional y los métodos directivos del sector público. La lista de los problemas incluye falta de objetividad, inadecuada construcción teórica, datos escasos y previsiones erróneas. La mayor parte de esta crítica refleja los efectos perniciosos de presunciones empíricas inadecuadas que subyacen, implícitamente, a las definiciones convencionales de la ciencia social. En las secciones finales de esta introducción destaco los argumentos que en cada capítulo inciden en esta afirmación. En la primera sección describo las que considero que son las principales presunciones.

Los sofisticados métodos y la lógica matemática de la ciencia social convencional están presididos por una imagen de «buena ciencia» que preside la investigación de las ciencias biológicas y físicas desde hace 
unos cien años. Este paradigma metodológico desfasado exige presunciones simplificadoras sobre estructuras y dinámicas que rara vez se cumplen en los sistemas políticos. Las principales presunciones implícitas, por lo general erróneas, son: 1) que los componentes de los sistemas políticos a gran escala (por ejemplo, Departamentos, Administraciones locales) son similares en sus partes y funciones, y 2) que las uniformidades en el comportamiento permanecen inmutables y no afectadas por la investigación científica.

Empleando el lenguaje más coloquial, a menudo se compara la investigación científica social con el estudio de los elefantes. Las disciplinas exploran distintos aspectos en profundidad. El conocimiento se acumula en las disciplinas y a lo largo del tiempo, porque las partes de la bestia se ensamblan en un esqueleto estable. La investigación científica, incluso la disección de la materia, no altera el significado de las partes, ni malogra el cuerpo de conocimientos acumulado (aunque pueda echar a perder a un elefante en particular). Cuando se comprende por completo el elefante, el movimiento de diversas especies en ambientes distintos puede explicarse y preverse a partir del conocimiento sobre huesos y tendones característicos. Por eso es posible estudiar los elefantes partiendo de presunciones de la ciencia social convencional. Las partes y funciones esenciales permanecen similares en el tiempo y el espacio, de manera que cabe generalizar, sin que la disposición de los científicos hacia el objeto altere tal circunstancia.

$\mathrm{Al}$ reflejar estas imágenes, los métodos cuantitativos de la ciencia social convencional se apoyan en presunciones tácitas sobre la comparabilidad, la descomponibilidad, la autonomía y la estabilidad de las unidades de análisis. Por ejemplo, la regresión funciona bien si son comparables en los distintos casos las variables y sus relaciones. En caso contrario, se da una mayor desviación en términos de error y son precisas ecuaciones distintas para otras muestras.

También los métodos experimentales están diseñados para un mun. do estático compuesto de casos comparables. En el auténtico experimento de laboratorio, el control y los casos experimentales son los mismos, excepto lo concerniente a la intervención. Dirigir un experimento de laboratorio implica también que el caso promedio es lo suficientemente parecido al investigado a lo largo del tiempo como para justificar el estudio.

Se supone que los métodos cuasiexperimentales adaptan los métodos experimentales puros a los sistemas sociales (CAMPBELL y STANLEY, 1963); los métodos estadísticos se ajustan a diferencias entre casos, interacciones entre variables y cambios en el tiempo. La cuestión consiste en aislar causas de comportamiento estables y persistentes - los huesos y tendones de los casos-. No obstante, estos ajustes producen resultados definitivos sólo cuando los casos son lo bastante parecidos 
como para limitar el número de ajustes, siendo la influencia de un ajuste dado aproximadamente la misma en los distintos casos y a lo largo del tiempo.

Son bien conocidos los problemas de adaptación de los métodos clásicos de las ciencias «duras» a los sistemas sociales. Derivan de las diferencias entre éstos y los sistemas físicos y biológicos. Los casos, como los individuos y las instituciones, son muy distintos, a pesar de las etiquetas comunes, como «irlandés», «legislatura» o «Administración local». El aislamiento de comportamientos distintos da lugar, con probabilidad y como resultado de su estudio científico (o periodístico), a variaciones en las uniformidades observables (vid. NAGEL, 1961).

Los científicos sociales saben que los sistemas sociales actuales difieren de los estudiados por ciencias más antiguas. Se les enseña que el comportamiento social depende del contexto, la cultura y la historia; que los hallazgos y valores de los científicos influyen en el comportamiento del sistema, y que las elaboraciones conceptuales sociales (variables) tienen sentidos distintos en función de los invididuos y las organizaciones.

Aunque sean obvias estas diferencias entre los sistemas sociales, biológicos y físicos, la mayoría de los métodos convencionales de la ciencia social, como los antes apuntados, estimulan a los investigadores a negar lo evidente. Estos métodos empíricos convencionales se centran en los aspectos repetitivos de los sistemas sociales que a menudo carecen de importancia política.

Así, la ciencia social convencional falla en la medida en que propicia que los investigadores hagan caso omiso de la dinámica de los sistemas sociales. Para mejorar su ciencia, los científicos sociales deben diseñar métodos que reflejan los rasgos esenciales de los sistemas sociales del mismo modo que los métodos de las ciencias físicas reflejan los rasgos básicos de los sistemas físicos. Las ciencias físicas generan conocimientos útiles porque sus métodos tienen validez externa para los sistemas físicos; las ciencias sociales producirán un conocimiento más útil cuanto más válidos resulten externamente sus métodos.

\section{CAPITULO 2: CAMBIO INTERADMINISTRATIVO}

Thomas ANTON critica lo que llama «interpretaciones globales» del cambio administrativo. Subyacentes a cada clasificación del pensamiento global -determinismo económico, responsabilidad administrativa, equilibrio de poder, legitimidad del sector público- existen imágenes no manifiestas del funcionamiento de un sistema político eficaz y eficiente. Estas imágenes idealizadas incluyen el gobierno modernizador que discurre paralelo a su moderna economía, el mercado competiti- 
vo, y el gobierno americano creado por los padres fundadores. El análisis, para los pensadores globales, consiste en comparar el funcionamiento real del mundo con el modo en que debería funcionar conforme a las teorías o imágenes no expresas. La desviación de hecho respecto de la teoría indica eficiencia, excesivo crecimiento de la Administración, declive institucional, etc. Lo que falta al pensamiento global es la articulación y las pruebas de las teorías sobre la mejora del funcionamiento político que subyace a las conclusiones.

Varias de las teorías globales que ANTON discute reflejan un modelo de superior rendimiento administrativo basado en imágenes de las ciencias físicas y biológicas. Con la etiqueta «dirección científica», este modelo fue de especial relevancia para los movimientos de reforma política de la primera mitad del siglo $\mathrm{xx}$. Los conceptos de jerarquía y autonomía siguen siendo hoy importantes, como presunciones empíricas y prescripciones sobre la Administración. Para aplicar la dirección científica, la Administración debería ser homogénea y estar centraliza$\mathrm{da}$, además de aislada de diversos ambientes locales. A medida que evoluciona la sociedad, se desarrollan las comunicaciones y se generalizan los problemas en sus efectos territoriales. En consecuencia, se formulan políticas en el nivel nacional y, en último extremo, en el internacional. Para que los directivos superiores localicen y apliquen leyes generales en estas vastas áreas, las organizaciones sociales y las unidades administrativas deben tener conductas y estructuras semejantes. Así, el aislamiento de unidades (Departamentos, funciones, personas) de distintos medios y la homologación de sus partes y funciones mejora la dirección.

Como indica el estudio de ANTON, el movimiento de reforma política, dirigido por esta visión de la dirección científica de principios del siglo $\mathrm{XX}$, ha recorrido ya su camino en gran parte. Actualmente están más de moda las teorías normativas basadas en mercados ideales y los principios de los padres fundadores. Sin embargo, irónicamente, las presunciones sobre lo que debería ser (la Administración debería estar controlada centralmente, homologada y aislada de medios locales) se han convertido en presunciones sobre lo que es (según las críticas, los programas de la Administración nacional distorsionan las prioridades de la Administración local). Así, los críticos de la Administración nacional centralizada (defensores de los mecanismos del mercado y de la Administración limitada de antaño) se unen a los defensores de la dirección científica, al presumir que el gobierno nacional controla el sistema federal.

ANTON dedica la segunda parte de su ensayo a los hechos relativos a la estructura y dinámica de la Administración americana. De hecho, el sistema político de Estados Unidos no es centralizado ni centralizable. La mayoría de las actividades en los planos estatal y local surgen 
de esos niveles, y las políticas nacionales se adaptan con el tiempo a las condiciones locales. Desde la base de medio siglo de doctrina teórica y empirica, ANTÓN rechaza también una perspectiva unidireccional del cambio político:

«Mis propias presunciones son más tradicionales y consistentes a partir de la experiencia sobre el federalismo americano. Asumo que el cambio en las relaciones sociales y administrativas sea constante y continuo como estado «normal» de cualquier sistema, siendo más probable que ese cambio sea cíclico que unidireccional; y que los cambios continúen desigualmente, con distintas y tal vez contradictorias consecuencias que harán posibles nuevos ciclos de cambio.»

\section{CAPITULO 3: ¿POR QUE CRECE LA ADMINISTRACION?}

Patrick LARKEY, Chandler STOLP y Mark WINER salen a cazar elefantes. Su crítica de la doctrina sobre el crecimiento administrativo (declive) consiste en que las escuelas teóricas y empíricas no coinciden: «En esta literatura como en muchas literaturas de las ciencias sociales, el trabajo inductivo carece de rigor teórico y el trabajo deductivo no tiene relevancia empírica.» Aceptando que existe un fenómeno llamado «crecimiento administrativo» (elefante) la investigación inductiva debería conducir a hallazgos de aplicación general, y las deducciones a partir de estos hallazgos deberían generar propuestas susceptibles de ser demostradas por pruebas ulteriores.

Con sus características actuales, la investigación sobre el crecimiento administrativo no se ajusta a la definición convencional de lo que se puede considerar una buena ciencia. Para empezar, el trabajo empírico es miope. Se seleccionan datos con el criterio de la disponibilidad, creyéndose que las relaciones construyen una teoría general a partir de los datos. Una consecuencia del empirismo miope es que los hallazgos no se acumulan. Por ejemplo, las mediciones de las dimensiones administrativas difieren, y así, los hallazgos varían según las mediciones. Además, las mediciones son demasiado ajustadas para sustituir la variable subyacente de la «presencia de la Administración»; por ejemplo, la mayoría olvida los efectos de los fallos judiciales. De modo similar, el empirismo miope fracasa a la hora de producir funciones generalizables - las ecuaciones de regresión son adecuadas en un país a lo largo del tiempo o en distintos países-. Los analistas intentan construir teorías generales sobre la causalidad a partir de tales hallazgos, pero como los casos son diversos, existen casi tantas posibles teorías generales como casos. A ello se añade que las teorías basadas en estu- 
dios inductivos consideran el crecimiento administrativo como inevitable e irreversible, porque éste fue el patrón observado durante la mayor parte del siglo XX.

Mientras el trabajo inductivo es miopemente empírico, la doctrina deductiva apenas es empírica. Esta doctrina hace uso de una sofisticada lógica matemática, pero sus presunciones simplificadoras no son realistas. Por ejemplo, la mayor parte de las teorías deductivas atribuye el crecimiento administrativo a un solo tipo de actor, como los burócratas, legisladores, votantes, grupos de intereses y empleados administrativos. Pero cada una de estas teorías es plausible, así que su acumulación sugiere que el crecimiento administrativo es producto de muchos factores, cada uno con sólo un efecto marginal. No obstante, en esta doctrina, el impacto de cada actor central en el crecimiento administrativo se modela como si fuera una ley subyacente y poderosa (un hueso o tendón).

LARKEY, STOPL y WINER concluyen con la importante observación de que las exigencias del método científico se satisfacen mejor con estudios longitudinales cuasiexperimentales que con estudios comparativos de sección cruzada (de una vez).

La ventaja de las comparaciones entre Administraciones o entre unidades de una misma Administración es la propia de experimentos con grupos de tratamiento y control. Si pudiéramos construir una situación en que las Administraciones sean más parecidas que diferentes, podríamos comprender causalmente las diferencias. Desafortunadamente, las Administraciones difieren en muchas dimensiones, y los controles necesarios sobrepasan los datos de que disponemos o podemos disponer. Es más fácil que las Administraciones conserven su identidad a lo largo del tiempo que evolucionen para parecerse a otras Administraciones.

\section{CAPITULO 4: SISTEMAS DE INFORMACION}

Los datos constituyen los cimientos del análisis científico, de la dirección y de las políticas. En su capítulo, John KING y Kenneth KRAEMER exploran posibilidades de mejorar el rendimiento administrativo reforzando los sistemas de información. Su conclusión no es optimista:

«Los estudios aquí citados indican que las esperanzas de mejorar la operatividad interadministrativa perfeccionando los sistemas de información son infundadas. Incluso en el plano administrativo local, donde es fácil encontrar sistemas operativos que funcionan bien, resulta difícil hallar sistemas avanzados de planificación y dirección que afecten significativamente la forma de 
llevar ambos a cabo. Existen continuos problemas de escasez de datos exactos y adecuados, de personal técnico para la utilización de la tecnología y de analistas que interpreten los datos. Interpretados éstos, pueden surgir problemas políticos. Estas dificultades se multiplican en el plano interadministrativo, porque los datos de las Administraciones locales a menudo no son comparables, y es difícil garantizar su exactitud. Han fallado los intentos de imponer la homologación, métodos directivos, exigencias de informes y otros objetivos de «sistemas» de arriba abajo. Además es probable que nunca alcancen el éxito, a menos que se reduzca la autonomía que hoy disfrutan las Administraciones locales y estatales.»

Como sugieren esta cita y los capítulos anteriores, la homologación y la dirección científica van de la mano. Los elementos que aportan datos no homologados, reflejo de la auténtica diversidad entre las Administraciones estatal y local, minan la dirección científica.

La primera mitad del capítulo 4 describe los intentos de mejora de la dirección en el plano local, introduciendo modelos formales o científicos de planificación y dirección. Estos esfuerzos han conducido a cambios permanentes y, presumiblemente, a mejoras en la aplicación de sistemas orientados a las operaciones, como los normativos, fiscales y de responsabilidad. Sin embargo, los intentos de diseñar y aplicar modelos de planificación, presupuestación y evaluación de rendimiento no han tenido tanto éxito. Cuanto más «política» sea la función, menos probable es que se aplique un modelo permanentemente.

Las diferencias de éxito en la aplicación de la dirección científica a las funciones operativas frente a las políticas, de naturaleza distinta, reflejan grados distintos de homologación y consenso. Como los elefantes, los sistemas operativos constan de partes relativamente tangibles e intercambiables. Cabe medir con sistemas independientes volúmenes de agua, propiedades y obligaciones. Y precisamente frente y por relación a las cuestiones y los retos políticos, estos sistemas de medida se consideran objetivos. De modo similar, los baremos fijos y los procedimientos pueden aplicarse de manera uniforme a medidas uniformes; y es posible realizar gran número de transacciones homologadas, valoradas desde una perspectiva política, porque son uniformes. La «normación adecuada» y la gestión financiera «honesta» implican el trato similar de los casos semejantes, y los sistemas identificados e informatizados contribuyen a la deseada homologación.

Así, la homologación fomenta la dirección científica y, en ciertas aplicaciones, puede equipararse a la «buena Administración». Las definiciones legales de baremos, medidas y procedimientos proporcionan modelos normativos convenidos en determinadas épocas políticas, y 
los funcionarios son responsables de que la realidad se ajuste a estos ideales. Además, debido al acuerdo general sobre modelos normativos de buena Administración, a menudo es posible transferir entre jurisdicciones políticas los sistemas financieros y otros de carácter operativo.

Por contra, los componentes y procesos de la planificación, la presupuestación y las actividades de evaluación están mal definidos y no se pueden generalizar a grupos de interés político, transacciones y períodos de tiempo. Los analisitas han intentado homologar estas funciones adoptando términos comunes, en términos de objetivos o metas y métricas comunes, como el dinero. Pero el valor y significado de los objetivos (y el dinero) están influidos por el horizonte temporal, la discusión, la lógica, el lenguaje, la experiencia vital y otros factores. Incluso los métodos complicados y rigurosos para definir, afinar o ponderar los objetivos de las agencias producen resultados «partidistas» para los extraños. Comó es casi imposible convenir sobre definiciones concretas de las metas de la Administración o sobre la decisiva importancia de la eficiencia (ahorrar dinero), no es frecuente que los modelos de dirección científica influyan en las decisiones políticas.

Dados sus hallazgos sobre la dificultad de aplicar los métodos de dirección científica a una sola unidad de la Administración local, KING y KRAEMER no se asombran de que estos métodos no contribuyan tampoco en medida significativa al gobierno de una nación compuesta de más de 80.000 unidades administrativas estatales, comarcales, locales y de distritos especiales. Las definiciones de datos, incluso los conceptos básicos de responsabilidad, se establecen legalmente a nivel estatal, y varían de Estado a Estado. Como sugieren los heroicos ajustes realizados por el personal del Censo de Administraciones de Estados Unidos, las funciones, las categorías de personal y los tipos de Administración se definen de distinto modo en los Estados; incluso dentro de los Estados, las definiciones reflejan tradiciones y características locales.

Los datos, incluso los financieros, no son lo bastante uniformes para apoyar otra cosa que informes nacionales agregados sobre la situación de la Administración local, e incluso estos resultados agregados son problemáticos con el paso del tiempo. Los análisis políticos verificados mediante regresiones y otras formas de estadísticas de sección cruzada, o mediante análisis cuasiexperimentales de casos «típicos», no permiten generalizaciones aceptables para los analistas o profesionales, que saben que las definiciones de los datos (y la mayor parte de las operaciones) no están homologadas en las Administraciones locales. 


\section{CAPITULO 5: UNA PERSPECTIVA DEMOGRAFICA}

Thomas MULLER atribuye los cambios en el tamaño del sector público de Estados Unidos a las tendencias demográficas y sus efectos en los gastos de la Administración. Esta atribución es acertada sólo en parte, lo que suscita importantes cuestiones ontológicas y epistemológicas sobre las ventajas relativas de las teorías empíricas (inductivas) frente a las normativas (deductivas).

Hasta mediados de los setenta, los análisis empírico inductivos (que consideran la diversidad administrativa) tienen un poder explicativo superior al de las teorías normativas, como las defendidas en los capítulos 6 a 8 y criticadas en los capítulos 2 y 3 . Las teorías que atribuyen el crecimiento administrativo a iniciativas nacionales no responden a los datos; los análisis empíricos que atribuyen el crecimiento a las consecuencias de la diversidad administrativa local, a su independencia y sensibilidad, sí.

Específicamente hasta mediados de los setenta, las tendencias demográficas - sobre todo la emigración- podrían explicar la mayoría de los incrementos de las inversiones del sector público, que se produjeron en los niveles estatal y local, no así en el nacional. La emigración, en cambio, se explica por las diferencias en las Administraciones locales. Las familias de clase media abandonaron las ciudades (sobre todo en el norte y medio oeste), que contaban con servicios públicos bien establecidos, por áreas residenciales y urbanamente no integradas (sobre todo en el sur y en el oeste), que carecían de servicios públicos. Esto ha aumentado los gastos per capita para servicios en las ciudades, tanto porque las instalaciones existentes (por ejemplo, las escuelas) pasaron a servir a menos clientes, como porque se quedaron familias más pobres e individuos de más edad, que necesitan más servicios. Simultáneamente, la Administración creció en lugares más pequeños y no incorporados, incrementándose los gastos agregados del sector público.

De esta forma, el crecimiento administrativo ha sido más rápido que el de la población o de los cambios en las necesidades y preferencias de ésta como conjunto; las cifras nacionales que indican una degradación de la eficiencia administrativa global durante los sesenta son exactas y significativas. Pero fueron las familias de clase media que actuaban por cuenta propia, y no los funcionarios federales, quienes iniciaron y se beneficiaron de la ineficiencia adminitrativa que se produjo. Los esfuerzos de los funcionarios federales y sus aliados de las grandes ciudades por servir mejor a las minorías y a los pobres pueden explicar parte de la emigración inicial de la clase media de las ciudades: estos esfuerzos exageraron las diferencias iniciales en los gastos del sector público entre las ciudades y otros lugares. Sin embargo, la mayor 
parte de los contrastes en ineficacia (coste per capita) entre lugares en declive y desarrollados son una función de la propia emigración - de desfases entre los cambios de población y de gastos-. Estos desfases reducen la eficiencia de la ciudad y aumentan la rural a corto plazo, lo que estimula la emigración.

Tras la ponderación por MULLER de los efectos de los movimientos de población, pocas variaciones de los gastos del sector público pueden explicarse por las acciones de grupos de interés, como burócratas de nivel nacional, políticos, funcionarios «públicos» autoatendidos y los pobres. Esto es así, porque los indicadores más inmediatos de bienestar de grupos de intereses liberales o democráticos tampoco varían mucho. El crecimiento de los gastos y empleo de la Administración nacional ha sido mucho más lento que el de los gastos estatales y locales, lo que limita las quejas sobre la centralización. Igualmente, el aumento de los salarios reales de los burócratas (en todos los niveles) ha sido pequeño (el grueso del aumento ha correspondido al número de burócratas, no a sus sueldos). Finalmente, los beneficios netos de las minorías, los pobres y cuasipobres - supuestos objetivos de las reformas liberales - han sido marginales.

No obstante, desde mediados de los setenta los análisis han revelado un cambio cualitatitivo en los factores determinantes del tamaño de la Administración (crecimiento/declive). El efecto en el gasto público de la emigración de las ciudades ha sido más pronunciado (los costes se han reducido como resultado de los despidos y cierres de instalaciones), mientras el efecto de la emigración a las ciudades ha sido menos pronunciado (se ha reducido el crecimiento de nuevos servicios). Dicho de otro modo, la presión sobre los gastos administrativos es evidente en todo tipo de Administración en la nación entera. Incluso las Administraciones que no han sufrido mandato expreso para controlar los costes han cortado los aumentos en impuestos y gastos.

La tendencia descendente uniforme en los gastos administrativos totales, que comienza a mediados de los años setenta, no fue anticipada por los análisis demográficos u otros de carácter cuantitativo del gasto administrativo; los empiristas predijeron más bien un crecimiento continuo. Como señala KIRLIN en el capítulo siguiente, predecir el cambio político requiere una teoría que incluya los movimientos políticos. KIRLIN ofrece una breve explicación del cambio de mediados de los setenta. Su análisis es similar al de los teóricos globales, que se critican en los capítulos 2 y 3 , con la importante diferencia de que KIRLIN identifica expresamente la fuente y el contenido de su marco normativo. Antes de mediados los setenta existía un contraste entre lo que el público quería (menos Administración, según las encuestas) con lo que obtenía (más gastos centrados en el interés, normas fiscales y regulación). Al final, el descontento público llegó a un punto crítico, y el movimiento pro limitación de impuestos barrió el país. 
Combinando las cifras de MULLER con el análisis de KIRLIN, descubrimos que, antes de mediados los setenta, el clima político toleraba el crecimiento de la implicación administrativa en mercados sociales y económicos, aunque el sentimiento contrario crecía. Después de mediados los setenta se alteraron las actividades administrativas en la nación y relaciones antes equilibradas entre las tendencias demográficas y los gastos del sector público (débiles en ciudades decadentes y fuertes en lugares en desarrollo) se volvieron más fuertes en las ciudades decadentes y más débiles en los lugares en crecimiento. Este caso indica que las perspectivas normativas de los fenómenos políticos (exactas o no) pueden condicionar el comportamiento social, a veces mediante la generación de alteraciones súbitas en lo que parecen ser leyes empíricas inmutables.

Juntos, los capítulos de MULLER y KIRLIN establecen un punto de inflexión en las preferencias de los autores por análisis puramente empíricos del funcionamiento administrativo frente a otros normativo-empíricos. Los tres primeros capítulos desacreditan las teorías normativas, al menos por dos razones: su marco de valor es a menudo implícito, y sus presunciones sobre la uniformidad nacional suelen ser erróneas. MULLER y KIRLIN desacreditan parcialmente el estilo de análisis empírico (agregación de estudios de casos longitudinales), preferido por los autores anteriores.

Los capítulos 6 a 9 exploran aproximaciones mixtas normativo-empíricas. Estas aproximaciones son potencialmente compatibles con métodos empíricos que asumen la diversidad administrativa y cambios de comportamiento en el tiempo. Se dirigen a los efectos probables de los esfuerzos políticos por alterar la conducta observable. Para ello, incorporan valores y otros factores humanísticos en predicciones del comportamiento del sistema social.

\section{CAPITULO 6: UNA PERSPECTIVA POLITICA}

John KIRLIN dice que los enfoques contemporáneos de la ciencia política y de la Administración pública, así como el análisis de políticas públicas operan desde una definición restringida e inadecuada de «Administración»; se centran en su manifestación observable: la prestación de servicios.

«Pero la prestación de servicios no es la función administrativa básica. La Administración es la institución de la sociedad que tiene la obligación singular de facilitar la articulación de opciones y la acción de la sociedad. Su capacidad de adopción de decisiones y de actuación son las dimensiones dominantes por las 
que se debe juzgar el funcionamiento administrativo. Las elecciones a menudo giran en torno a la prestación de servicios, y también la acción, pero la capacidad de elección y acción no es sinónimo de prestación de servicios. El patrón de capacidad tiene profundas raíces en la filosofía política occidental, fue la preocupación básica de los diseñadores de la Constitución de Estados Unidos y halla su moderna expresión en diversas críticas importantes del funcionamiento del sistema político de Estados Unidos.»

En definición de KIRLIN, la Administración (y la política) trata en realidad de la formulación, difusión y articulación de perspectivas políticas. Se trata de un proceso en el curso del cual las ideas se tornan leyes e instituciones, sirviéndose intereses a veces restringidos y a veces populares. KIRLIN utiliza su definición de Administración para ilustrar fallos muy difundidos de la ciencia política y de los estudios políticos. También construye un marco más general para evaluar el funcionamiento administrativo sobre la base de su más amplia definición de Administración.

La ciencia social ha sido acusada de fomentar la centralización, la homologación, el elitismo y los intereses de los científicos sociales a expensas de la flexibilidad, el pluralismo, la democracia y la objetividad. KIRLIN destaca estos problemas y los atribuye a la definición restrictiva de la Administración y la orientación dominante en los ámbitos de la ciencia política y de la Administración pública y del análisis de políticas. La concentración actual del interés de los mismos en la prestación de servicios, las instituciones observables y los valores de los agentes políticos con capacidad de decisión y de sus clientes con poder económico-social restringe la actividad intelectual rigurosa al statu quo. Este sesgo conservador contrasta a menudo con los valores confesados de los científicos sociales que dirigen la investigación.

El estudio de KIRLIN indica también que el sesgo político de la ciencia social no se limita a la llamada investigación aplicada. El sesgo deriva de la definición de ciencia que cimenta la revolución empírica y el positivismo social. Esta aproximación estrictamente empírica centra los análisis en las consecuencias de la elección política-instituciones establecidas y observables. Como los ciudadanos pueden tener preferencias políticas que favorezcan la modificación de las instituciones establecidas, limitar la investigación básica al comportamiento observable tiene implicaciones conservadoras.

El grueso del ensayo de KIRLIN se dedica a la construcción de un marco más realista para la evaluación del funcionamiento del sector público. A diferencia del propio de la dirección científica, su marco es compatible con la diversidad y flexibilidad que caracteriza el sistema 
político de Estados Unidos. La homologación se aplica escasamente y sólo si existe acuerdo generalizado al respecto. Si existe consenso sobre objetivos y métodos viables de articulación, se autorizan controles y directivas homogéneos, detallados y centralizados. Si el acuerdo versa sobre los objetivos, pero no sobre una estrategia única de articulación, se recomiendan los incentivos (recompensas y sanciones por resultados). Si varían los objetivos y los mecanismos de articulación, se recomienda la negociación interactiva y las estrategias de aprendizaje.

KIRLIN dice que su marco de evaluación del rendimiento del sector público es normativo - no finge «objetividad científica»- Pero su marco de investigación y dirección es atractivo desde la perspectiva de la ciencia.

Es más neutral políticamente que la dirección científica, en el sentido de que no se orienta hacia un conjunto de presunciones (sobre la semejanza y la autonomía) que fomenten la centralización. Su poder de predicción también es mayor que el de los análisis empíricos miopes, y en este sentido es mejor teoría empírica.

\section{CAPITULO 7: UNA PERSPECTIVA FINANCIERA PUBLICA}

Como señala KIRLIN, los defensores de la cuantificación en el ámbito de la ciencia política eran positivistas lógicos que temporalmente arrojaron del establecimiento científico-disciplinar a los teóricos deductivos y normativos. Felizmente, los economistas del subsector de la Hacienda pública mantuvieron vivas las perspectivas teórico-normativas sobre temas políticos fundamentales, como la estructura de la Administración. También progresaron en la cuantificación de estas teorías y su utilización en la investigación empírica. Richard ARONSON y Eli SCHWARTZ estudian la doctrina sobre la Hacienda pública, que es matemática, normativa y empírica. Aunque sigue habiendo problemas, los científicos sociales han avanzado considerablemente en la cuantificación de modelos normativo-empíricos de elección política.

Aunque la doctrina sobre la Hacienda pública es muy matemática, el capítulo de ARONSON y SCHWARTZ, como las conclusiones de JOHNSON y LEWIN, emplean el lenguaje ordinario. El objetivo es proporcionar un análisis de este campo como fuente de comprensión y control del funcionamiento del sector público. Se ponen de relieve aspectos de teorías políticas (capítulo 7) y de estructuras directivas (capítulo 8), que han sido o no diseñados con éxito.

Las teorías de la Hacienda pública ofrecen una base intelectual para los programas demócratas y republicanos. Las teorías de los «bienes públicos» justifican la expansión de los programas nacionales y la implicación en asuntos estatales y locales asociadas con los demócratas. 
En general, la doctrina de los bienes públicos favorece la centralización para cubrir objetivos de equidad. En contraste, la doctrina de la «elección pública» proporciona apoyo a la tesis republicana con teorías que aplican la lógica de los mercados eficientes al diseño de políticas en el sector público. Esta doctrina se centra en la eficiencia y generalmente favorece la descentralización.

Ambos cuerpos de doctrina encuentran dificultades al someterse a pruebas empíricas en el mundo real, donde son mudables las conexiones entre centralización y equidad y descentralización y eficiencia. La principal debilidad de las teorías clásicas de la Hacienda pública es que son estáticas. Modelan y predicen los efectos de una política sólo en la primera fase, donde la política crea incentivos a los que reaccionan los actores (individuos, funcionarios locales, etc.). Se omiten factores que se desarrollan con el tiempo para cambiar, y a menudo invertir, las respuestas iniciales.

La más seria de estas omisiones relacionadas con el tiempo es la de los nuevos incentivos creados por las reacciones iniciales. ARONSON y SCHWARTZ ilustran este problema que afecta a las teorías de la «elección pública»:

«Los hallazgos de las pruebas empíricas de la hipótesis Tiebout y sus posibles implicaciones son típicos. La teoría identifica la conducta racional de un conjunto dado de actores en ciertas condiciones, y en general, la gente actúa como se ha previsto. No obstante, sus acciones cambian las condiciones de otros, que reaccionan de forma que alteran las condiciones iniciales y los dictados del interés propio. Ello desemboca en un comportamiento que alternativamente confirma y desacredita las teorías que relacionan centralización y descentralización con equidad y eficiencia. A veces, la acción central promueve la eficiencia; a veces, la descentralización promueve la equidad.»

Sin embargo, Aronson y SCHwarTz están alentados por las aplicaciones de la investigación. Señalan que la preparación de los funcionarios ha mejorado hasta el punto de que muchos saben diseñar y aplicar modelos matemáticos de políticas. Estos modelos se vuelven sofisticados al anticipar la retroalimentación -reacciones y respuestas en el tiempo- Se recompensa el realismo de los profesionales y se castigan las malas predicciones; deben conceptualizar el comportamiento de autores centrales en el contexto y son responsables de los fallos. Ello estimula el desarrollo de modelos implícitos y explícitos que consideran factores como los cambios de los incentivos en el tiempo. 


\section{CAPITULO 8: MODELOS DE DIRECCION Y RESPONSABILIDAD}

Los modelos normativo-empíricos estudiados por Ronald JOHNSON y Arie LEWIN se centran en el funcionamiento de los entes administrativos, en lugar de los sistemas interadministrativos. La mayor parte de estos métodos proceden de los ámbitos de la ciencia de la dirección y la responsabilidad. El modelo idealizado para la aproximación de la ciencia de la dirección es el método de ingeniería para comprobar el nivel superior de eficiencia de una máquina. Existen serios problemas para aplicar este modelo a los sistemas sociales.

«Medir la eficiencia de una organización es el centro crítico de la evaluación de funcionamiento. Para realizar esta tarea es preciso relacionar la utilización de recursos con la producción de resultados. Idealmente, las medidas de eficiencia utilizan el conocimiento del proceso productivo y su potencial de rendimiento. Por ejemplo, el funcionamiento teórico de un motor de combustión interna se calcula a partir de sus datos de diseño, y su eficiencia actual se relaciona entonces con la potencial. En el caso de las organizaciones del sector público, tales cálculos de eficiencia no son factibles en el presente al no ser posible especificar el sistema productivo organizacional o computar su teórica capacidad productiva. Además, carecemos de medidas de resultado únicas que recojan satisfactoriamente todo el abanico de objetivos del sector público. El problema básico que plantea la transformación de medidas de resultado no proporcionadas en un único indicador de rendimiento agregado permanece, aunque algunos métodos prometen producir una valoración de la productividad global.»

No es sorprendente que los métodos de la ciencia de la dirección funcionen mejor al aplicarse a sistemas de componentes en gran parte físicos. Por ejemplo, se utilizan regularmente en las decisiones sobre asignación y mantenimiento de equipos. Como vimos antes, también funcionan para aspectos de las organizaciones (como los sistemas contables), homologados por acuerdos profesionales y políticos. Sin embargo, la mayoría de las técnicas debatidas por JOHNSON y LEWIN extienden los modelos de mejora a procesos con elementos políticos, como la presupuestación. Como indica la cita, la falta de acuerdo sobre la definición adecuada del rendimiento administrativo constituye un serio problema en estas áreas.

Algunos métodos de la ciencia de la dirección debatidos por JOHNSON y LEWIN bajo la categoría de «modelos de objetivos» están dise- 
ñados para tratar el problema de la definición de objetivos. A menudo, estos métodos se enfrentan con diversos objetivos, que concilian y ordenan, en general jerárquicamente. La medición del rendimiento, descrita en la última sección del capítulo, se enfrenta también con los esfuerzos por definir los objetivos en términos de expectativas medibles de la conducta organizacional y los impactos de las políticas.

El campo con la más larga historia de definición de metas medibles y de modelos de igual naturaleza, sin embargo, es el ámbito tradicional de la contabilidad. La investigación aquí exige reunir profesionales de prestigio, que representen a los entes afectados, para plantear prácticas «aceptadas» y «preferidas», a fin de conservar e informar transacciones financieras. Posteriormente se transmiten estos planteamientos a efectos de estudio y comentario. Presumiblemente, la orientación resultante es lo bastante cercana a la práctica existente como para representar un objetivo de rendimiento factible en el caso medio. La comprobación de este objetivo se supervisa por contables en el campo, y es posible castigar mediante el proceso político las violaciones de los modelos de contabilidad.

Como señalé antes, el éxito relativo a lo largo de los años de la profesión contable en la definición, supervisión y refuerzo de modelos de transacciones financieras se encuentra detrás de esfuerzos relativamente exitosos para aplicar la ciencia al sector público. Como destacan JOHNSON y LEWIN, sin embargo, el progreso futuro exige mayor acuerdo sobre qué es información financiera esencial y sobre los modelos de transmisión de esta información. En realidad, mayor conformidad administrativa con los modelos contables aceptados mejoraría en gran medida las perspectivas de aplicar a la Administración la dirección científica. También aumentaría el conocimiento de los ciudadanos y el control político.

En conjunto, el análisis de JOHNSON y LEWIN atestigua la importancia de las actividades profesionales y políticas para definir, supervisar y reforzar los modelos de funcionamiento. Ello refuerza la tesis de KIRLIN en el sentido de que las instituciones políticas están socialmente constituidas.

\section{CAPITULO 9: UNA PERSPECTIVA DE CIENCIA MARCO}

En el último capítulo bosquejo un marco intelectual para la ciencia política que pretende ser lo bastante amplio para abarcar el contenido de otros capítulos. Lo llamo «ciencia marco». El concepto procede de Herbert A. SimON (1969), que lo utiliza para describir las ciencias de lo artificial, ciencias que tratan rigurosamente objetos de investigación construidos por diseño, normalmente por humanos. 
La ciencia política marco operativiza la definición política de KIRLIN como la adopción de decisiones para la sociedad. La política incluye los debates sobre valores y la utilización de unos valores sobre otros. Los procesos políticos establecen, cambian y derriban las reglas del juego de otras ciencias sociales, como la economía y la sociología.

A pesar de su amplitud, la ciencia política marco es cuantitativa. Incluye rigurosos métodos normativos para definir, refinar e institucionalizar valores como los que se encuentran en la ciencia de la dirección y decisión y en la Hacienda pública. También engloba rigurosos métodos empíricos, incluyendo la determinación de hasta qué punto los procesos sociales están bien ordenados o sujetos a cambio cualitativo (estos métodos se apuntan en el último capítulo).

La ciencia política marco que contemplo e intento describir en el último capítulo no existe aún. Estudiando disciplinas, podemos descubrir sus componentes, pero la articulación de éstos en un paradigma aún no se ha logrado.

\section{REFERENCIA BIBLIOGRAFICA}

CAMPBELl, Donal T., y STANLEY, Julian 'G. (1963), Experimental and QuasiExperimental Desings for Research, Chicago, Rand McNally.

NAGEL, Enest (1961), The Structure of Science: Problems in the Logic of Scientific Explanation, Nueva York, Harcourt Brace y World.

SimON, Herbert A. (1969), The Sciences of the Artificial, Cambirdge, Mass., MIT Press.

Traducción: Diego Agustín Carrasco PradaS 